\title{
A Randomized Prospective Comparative Study of Single Versus Combination Chemo-radiation in Locally Advanced Head and Neck Cancers
}

\author{
Manish Ahirwar, Veenita Yogi* and Om Prakash Singh \\ ${ }^{1}$ Senior Resident, Department of Radiation Oncology, Gandhi Medical College, Bhopal, India \\ ${ }^{2}$ Associate Professor, Department of Radiation Oncology, Gandhi Medical College, Bhopal, India \\ ${ }^{3}$ Professor \& Head, Department of Radiation Oncology, Gandhi Medical College, Bhopal, India
}

Submission: May 17, 2019; Published: July 19, 2019

"Correspondence Author: Dr. Veenita Yogi, Associate Professor, Department of Radiation Oncology, Gandhi Medical College, Bhopal, India

Abstract

Aim: The present study compares a single and combination chemotherapy regimen in concurrent settings with radiotherapy for locally advanced head and neck squamous cell cancer in terms of local control of disease, toxicity profiles, and progression-free survival.

Background: Head and neck squamous cell cancer (HNSCC) can be successfully managed with a well-coordinated multidisciplinary approach. The most commonly used approach is combined radical radiotherapy with chemotherapy. Present study compared Paclitaxel with a combination chemotherapy regimen including Cisplatin and Paclitaxel as concurrent chemoradiation in terms of local control of disease, toxicity profile and progression-free survival.

Materials and Method: In this randomized prospective study 100 patients of locally advanced HNSCC were included. Patients were divided into two groups, one group received paclitaxel alone while other received paclitaxel with cisplatin as concurrent chemotherapy with external beam radiotherapy (EBRT) at a tertiary care Centre of central India. Both the groups were comparable with respect to age, sex, and performance status of patients.

Results: On overall comparison log rank test shows a chi square statistic of 4.299 and a p value of 0.038 suggestive of significant difference between the progression-free survival of two arms while difference in toxicity profile of two arms was comparable.

Conclusion: Present study suggests progression-free survival benefit of using paclitaxel and cisplatin both together as concurrent chemotherapy with comparable toxicity profile to that of paclitaxel alone.

Keywords: Paclitaxel cisplatin; Concurrent Chemo Radiation; Locally Advanced Head and neck cancer

Abbreviations: HNSCC: Head and Neck Squamous Cell Cancer; EBRT: External Beam Radiotherapy; CCRT: Concurrent Chemo-Radiotherapy; KPS: Karnofsky Performance Score; PFS: Progression Free Survival; WDSCC: Well Differentiated Squamous Cell Cancer; MDSCC: Moderately Differentiated Squamous Cell Cancer; PDSCC: Poorly Differentiated Squamous Cell Cancer

\section{Introduction}

Cancer as an illness of man is a serious health problem, particularly in developing countries as it is one of the most serious causes of morbidity and mortality among a major part of the world's population. Head and neck squamous cell carcinoma (HNSCC) are the sixth commonest cancer in the world. Five lakh new cases of HNSCC are diagnosed worldwide per year [1]. In India alone, 2.5 lakh new patients are diagnosed of whom about three-fourths are in an advanced stage [2]. The main treatment modalities used in the treatment of head and neck cancers are surgery, radiotherapy and chemotherapy. The treatment modality to be used is selected on the basis of knowledge of the natural history of disease as well as on the understanding of the treatment plan chosen and its complications. Tremendous revolutionary changes have taken place in the management of cancer over the past decades and now it is a generalized notion that cancer can be successfully managed by a well-coordinated multidisciplinary approach. One of the most commonly used approaches has been to combine radical radiotherapy with chemotherapy, and evidence has emerged, that this concurrent chemo-radiotherapy (CCRT) modality can achieve not only 
better local control, but also increased survival in advanced head and neck cancer [3-8]. Present study compares a single drug concurrent chemotherapy regimen of paclitaxel with a combination chemotherapy regimen with added cisplatin to paclitaxel in terms of local control of disease, i.e. clinical response to treatment, progression free survival and toxicity profile.

\section{Aim and Objectives}

To evaluate the efficacy of Paclitaxel with Cisplatin in comparison to Paclitaxel alone as concurrent chemotherapy regimen in terms of response at the primary site of tumour.

i. To analyses treatment responses in terms of local control of disease.

ii. To compare toxicity profiles of the two regimens in terms of the most common toxicities reported in these regimens.

iii. To evaluate and compare progression free survival.

\section{Materials and Methods}

This is a randomized prospective study that includes a total of 100 histopathologically proven patients with locally advanced squamous cell carcinoma of head and neck presenting at a tertiary care Centre of central India between October 2015 up to August 2017. Study was conducted after approval from institutional ethical committee and a written informed consent has been taken from each patient included in the study. All patients were treated with external beam radiotherapy (EBRT) up to 66-70 Gy. The spinal cord dose was limited to 4600 cGy i.e. up to 23 fractions and patients were stratified into two groups according to their concurrent chemotherapy regimen.

i. Arm A: Patients received paclitaxel $\left(60 \mathrm{mg} / \mathrm{m}^{2}\right)$ with cisplatin $\left(20 \mathrm{mg} / \mathrm{m}^{2}\right)$ as concurrent chemotherapy with conventional radiotherapy.

ii. Arm B: Patients received paclitaxel $\left(60 \mathrm{mg} / \mathrm{m}^{2}\right)$ alone as concurrent chemotherapy with conventional radiotherapy.

Treatment response was evaluated according to RECIST (Response Evaluation in Solid Tumors) criteria. Statistical analysis was done by using Microsoft Excel and Epi-info version 7. Means were calculated for each of the quantitative values and then comparisons were made using independent t-test. Chi square test was used for comparison of response between the two arms, and Kaplan Meier analysis was done for survival analysis, while for comparison of progression-free survival of both arms log rank hypothesis was used. $\mathrm{P}$ value $<0.05$ was taken as statistical significant.

\section{Results}

A total of 118 patients were included in the study, out of which 50 patients were in Arm A and 50 in Arm B while nine patients of each arm were lost to follow up during or after treatment. Each patient in Arm A received paclitaxel and cisplatin both as concurrent chemotherapy, whereas Arm B patients received paclitaxel alone as concurrent chemotherapy along with EBRT. The median age of patients in Arm A was 50 years (with a range of 30-65 years) and that in Arm B was 43 years (with a range of $31-70$ years) ( $p=0.64)$. Overall $88 \%$ of patients were male and only $12 \%$ were female. In Arm A 44 (88\%) patients were male while $6(12 \%)$ patient was female. In Arm B 39 (78\%) patients were male and only $11(22 \%)$ were female $(p=0.18)$. At the time when patients have been taken for CCRT ten patients had a Karnofsky performance score (KPS) of 90, 89 had a KPS of 80 and one patient a KPS of 70. According to the inclusion criteria of the study, patients with advanced HNSCC (Stage III and Stage IV) were included in the study. In Arm A 43 (86\%) patients belong to stage IV disease while only 7 (14\%) patients were of stage III disease. In Arm B 40 (80\%) belong to stage IV disease while $10(20 \%)$ patients were of stage III disease $(p=0.42)$. In Arm A $22(44 \%)$ patients were have well differentiated squamous cell carcinoma (WDSCC), 23 (46\%) were have moderately differentiated squamous cell carcinoma (MDSCC) while 5 (10\%) of patients were have poorly differentiated squamous cell carcinoma (PDSCC).

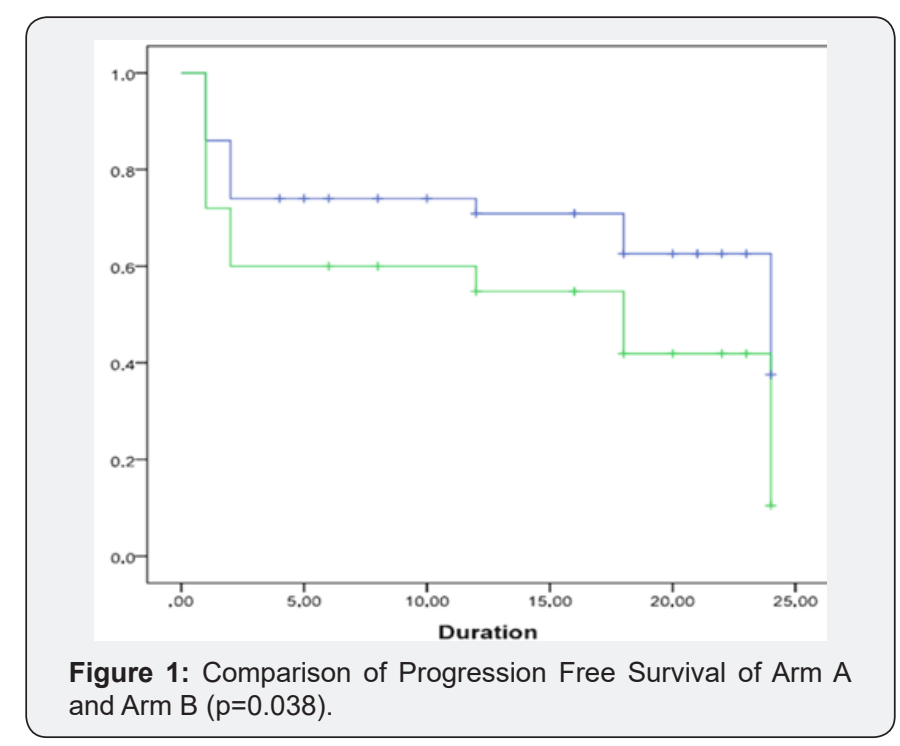

In comparison Arm B is having 23 (46\%) of cases of WDSCC, $18(36 \%)$ of MDSCC and $9(18 \%)$ of PDSCC ( $p=0.41)$. Most of the patients in the study were having buccal mucosa cancer 27 (27\%) followed by tongue 21 (21\%), Supraglottis 11 (11\%), and pyriform fossa 9 (9\%). All the patients showed response in both the groups. In Arm A, complete response was observed in 37 (74\%) patients and $13(26 \%)$ patients showed partial response while on further follow-up at 12 months, 18 months and 24 months 1 (2\%), 2 (4\%) and, 2 (4\%) patients suffered recurrence at the primary site respectively. In Arm B, complete response was seen in $60 \%$ and partial response in $40 \%$, while on further follow up at 6 months, 12 months, 18 months and 24 months 2 (4\%), $1(2 \%), 3(6 \%), 3(6 \%)$ patients suffered recurrence at the primary site respectively. The chi-square statistic is 2.2162 with a p-value of 0.14 which suggests that in terms of the number of 


\section{Cancer Therapy \& Oncology International Journal}

patients, Arm A patients showed a more complete response, but the difference was statistically not significant. Progression Free Survival (PFS) was observed for both the groups for a followup of 24 months. The difference was statistically significant ( $p$ value -0.038) Figure 1, as Group A showed a higher PFS rate than Group B.

The median follow-up time for group A was 13 months while 20 months for arm B. The median survival time in group A was 24 months (lower limit- 17.16 and upper limit- 30.83 with $95 \%$ $\mathrm{CI}$ ) and in group B it was 18 months (lower limit- 4.31 and upper limit- 31.684 with $95 \% \mathrm{CI}$ ) while the overall median survival time was 24 months (upper limit- 18.71 and upper limit- 29.28 with 95\% CI). Overall mean survival time was 15.4 (upper limit13.28 and lower limit- 17.42 with a std. error of 1.057). On overall comparison Log rank test shows a chi square statistic of 4.29 and a $p$ value of 0.038 suggestive of significant difference between the progression-free survival of two arms which is more for arm A (Figure 1). As comparison was made between the two groups according to their toxicity profiles, no significant difference was seen (for mucositis $\mathrm{p}=0.28$, skin $\mathrm{p}=0.89$, GIT $\mathrm{p}=0.051$, hematological $\mathrm{p}=0.08)$ but all the toxicity observed was more in arm A (Table 1), (Figures 2 \& 3).

Table 1: Comparative Toxicity Among Arm A and Arm B

\begin{tabular}{|c|c|c|c|c|c|c|c|c|}
\hline \multirow{2}{*}{} & \multicolumn{4}{|c|}{ Arm B } & \multicolumn{3}{c|}{ Arm B } \\
\cline { 2 - 8 } & Grade 1 & Grade 2 & Grade 3 & Grade 4 & Grade 1 & Grade 2 & Grade 3 & Grade 4 \\
\hline Mucosa & $15(30 \%)$ & $13(26 \%)$ & $13(26 \%)$ & $9(18 \%)$ & $7(14 \%)$ & $17(34 \%)$ & $15(30 \%)$ & $11(22 \%)$ \\
\hline Skin & $7(14 \%)$ & $19(38 \%)$ & $16(32 \%)$ & $8(16 \%)$ & $7(14 \%)$ & $17(34 \%)$ & $15(30 \%)$ & $11(22 \%)$ \\
\hline GIT & $15(30 \%)$ & $17(34 \%)$ & $8(16 \%)$ & $10(20 \%)$ & $6(12 \%)$ & $16(32 \%)$ & $18(36 \%)$ & $10(20 \%)$ \\
\hline Hematological & $9(18 \%)$ & $18(36 \%)$ & $15(30 \%)$ & $8(16 \%)$ & $3(6 \%)$ & $18(36 \%)$ & $12(24 \%)$ & $17(34 \%)$ \\
\hline
\end{tabular}

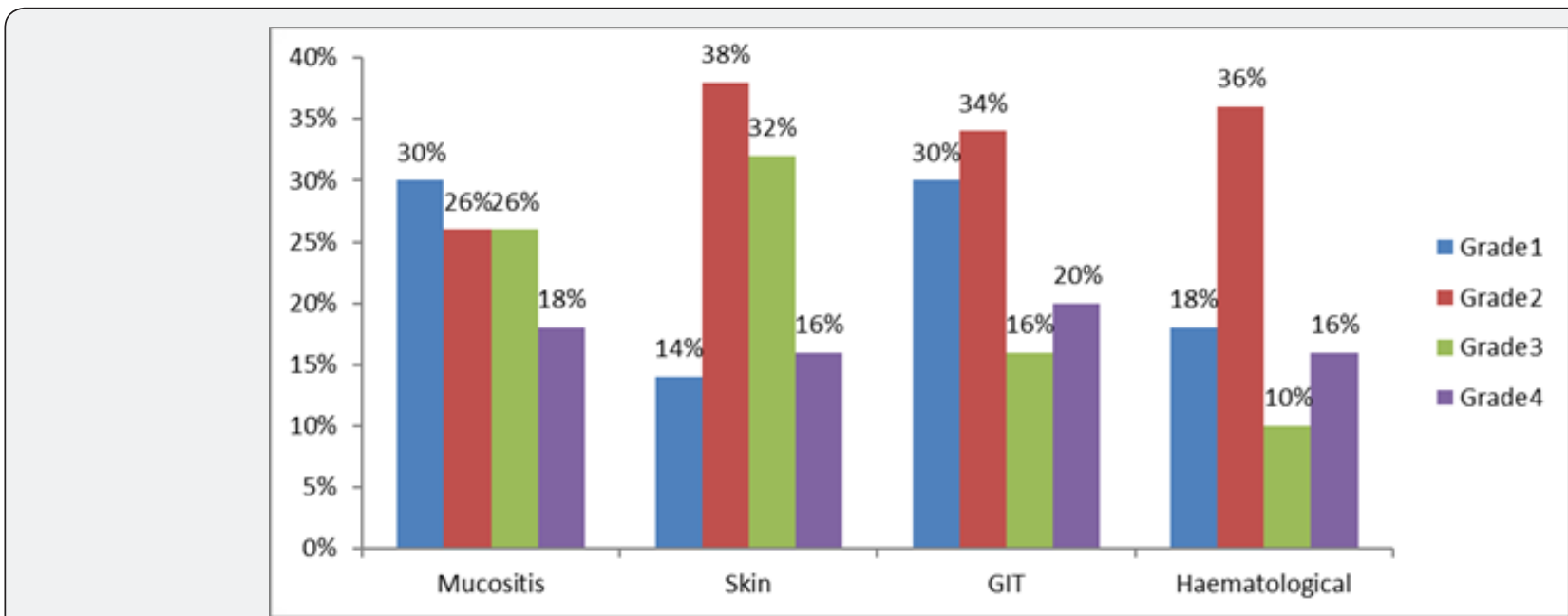

Figure 2: Number of patients showing various toxicities at follow-ups during radiotherapy in Arm A.

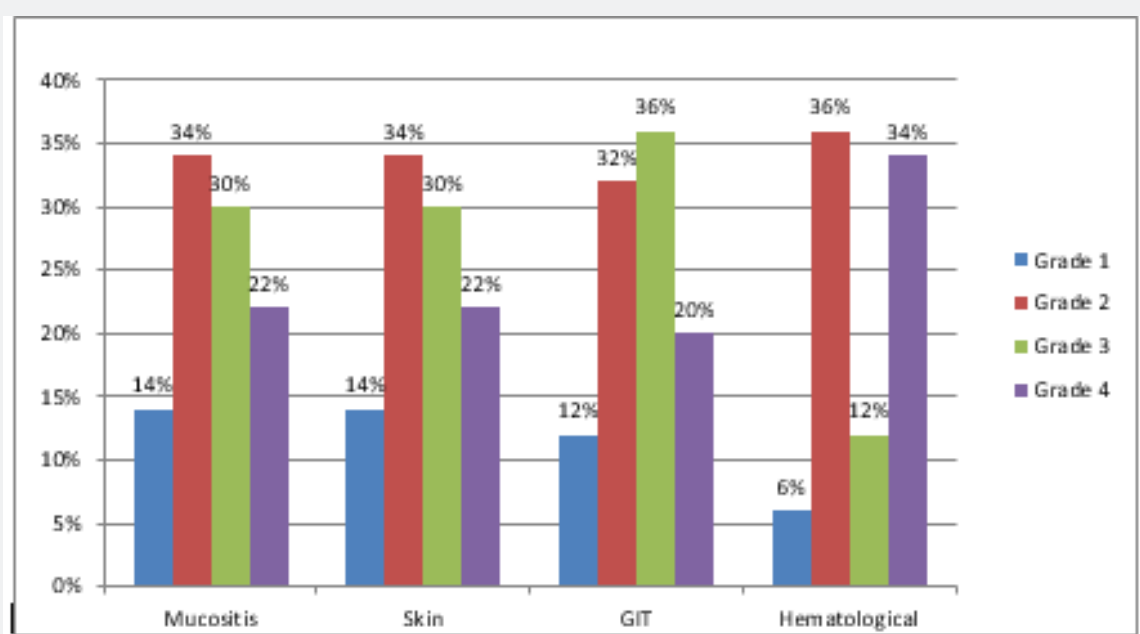

Figure 3: Number of patients showing various toxicities at follow-ups during radiotherapy in Arm B. 


\section{Cancer Therapy \& Oncology International Journal}

\section{Discussion}

The benefits of concurrent chemotherapy in patients with HNSCC have been intensively investigated since last few decades. HNSCCs are remarkably sensitive to chemotherapeutic drugs such as 5-fluorouracil, cisplatin, carboplatin, and the taxanes. Despite a high rate of clinical and pathologic responses have been consistently reported in the literature, a consistent survival benefit in the randomized setting has not been demonstrated. The meta-analysis by Pignon et al. suggested a small but significant absolute survival benefit with concurrent chemotherapy and radiation [4]. Randomized trials in locally advanced head and neck cancer have consistently shown a survival benefit with the use of concurrent radiotherapy and platinum-based chemotherapy [3,9-11]. This prospective study was conducted on patients presenting with HNSCC at a tertiary institute of central India with a schedule of weekly cisplatin and paclitaxel administered as CCRT in one arm and paclitaxel alone as CCRT in another arm.

In the early 1990s, Merlano et al. conducted a study on 157 previously untreated patients with advanced squamous HNSCC and randomly treated them with alternating chemotherapy and radiotherapy or radiotherapy alone [12]. In this study, the complete response rate was 43 and $22 \%(\mathrm{P}=0.03)$ in combined therapy and radiotherapy arms, respectively. The median survival was 16.5 months in the combined therapy group and 11.7 months in the radiotherapy group $(\mathrm{P}<0.05)$. This study concluded the benefit of adding chemotherapy concurrently with EBRT to achieve a better response and survival. Earlier since the start considering concurrent chemoradiotherapy as main treatment modality for HNSCC Cisplatin was the most commonly used single drug but in 1990's Forrestier et al. [13]. used Taxol as concurrent chemotherapy with EBRT and achieved good treatment response. In our study the intent of involving two concurrent chemotherapy regimens was to recognize the better concurrent chemotherapy regimen in terms of better locoregional control, progression free survival with acceptable toxicity.

Suntharalingam et al. [14] from the University of Maryland studied carboplatin $100 \mathrm{mg} / \mathrm{m} 2$ and paclitaxel $45 \mathrm{mg} / \mathrm{m} 2$ concurrently with radiotherapy for locally advanced HNSCC and reported a 3-year disease-free survival and OS of $48 \%$, with a median follow-up of 30 months. Similarly in our study arm A using both (Paclitaxel and Cisplatin) drugs showed improved locoregional response and PFS while the patients in this arm also suffered more toxicity, as compared to arm B where patients had received only paclitaxel as concurrent chemotherapy, but the difference of toxicity profile was not much significant in terms of grading. Toxicities observed in all the patients were managed with supportive treatment and all the patients were managed to complete treatment within time. In order to maintain body weight, total enteral nutrition therapy was performed using a nasogastric tube while Filgrastim was used in patients with grade III+ mucositis. The weekly delivery of paclitaxel and cisplatin was given on an outpatient basis, considering ease of delivery, patient compliance, and cost-effectiveness. Though the radiosensitizing effects of a combination of paclitaxel and cisplatin cause increase in mucositis but also leads to higher complete response rates. Severe mucositis was the predominant toxicity occurred in the majority of patients, which led to minor interruptions in EBRT and chemotherapy. The high rates of mucositis precluded further use of this regimen in the clinical setting. Subsequent head and neck chemoradiotherapy trials by the Brown University Oncology Group have adopted the low-dose paclitaxel and carboplatin combination as a standard regimen $[15,16]$.

Garden et al from the RTOG reported their randomized phase II study in which the study arm utilizing cisplatin, paclitaxel, and daily RT was recommended for further phase III testing [17]. Suntharalingam et al. reported similar responses with the use of paclitaxel $45 \mathrm{mg} / \mathrm{m} 2 /$ week, carboplatin $100 \mathrm{mg} / \mathrm{m} 2 /$ week and daily radiotherapy in locally advanced HNSCC while Flood et al. [18] used paclitaxel at a dose of $60 \mathrm{mg} / \mathrm{m} 2$ with carboplatin 1AUC and achieved similar results to our study. Our study, with a shorter follow up reveals the curative potential of paclitaxelcisplatin chemoradiotherapy in this poor-prognosis setting with acceptable toxicities. Similar to these studies Agulnik M et al. [19] also conducted a study involving similar regimens of CCRT as that of our study (carboplatin was used in place of cisplatin) in post-operated patients of head and neck cancer and achieved somewhat similar results as that of our study. In summary, treatment of patients with locally advanced inoperable head and neck cancers with concomitant weekly paclitaxel, cisplatin, and conventional external beam RT is feasible. The overall response rate of $100 \%$ and the high frequency of pathologic complete responses were impressive, and the progression-free survival was very encouraging. Single agent paclitaxel or cisplatin has been used by many authors as a concurrent chemotherapy with favorable response and acceptable toxicities. In our study single agent paclitaxel was compared with the combination of paclitaxel and cisplatin, which are both well accepted standard regimens for HNSCC in adjuvant, neoadjuvant, and concurrent settings. Our study results suggest benefits of a combination chemotherapy regimen (Paclitaxel and Cisplatin) in terms of better locoregional control and progression free survival in concurrent settings with acceptable and manageable toxicities so may not need further dose adjustments.

\section{Conclusion}

Present study suggests progression-free survival benefit of using paclitaxel and cisplatin both together as concurrent chemotherapy with comparable toxicity profile to that of paclitaxel alone. So finally, we can conclude that paclitaxel as a concurrent chemotherapy drug is as much effective as other 


\section{Cancer Therapy \& Oncology International Journal}

chemotherapy drugs used along with radiotherapy in HNSCC and an addition of cisplatin increases its effectiveness without much fluctuation of toxicity profile.

\section{References}

1. Rousseau A, Badoual C (2012) Head and Neck: Squamous cell carcinoma: an overview. Atlas Genet Cytogenet Oncol Haematol 16 (2): 145-55.

2. Desai C (2008) Squamous cell carcinoma of the head and neck region: Insights from the American Society of Clinical Oncology presentations. Indian J Cancer 45(3): 90-92.

3. Adelstein DJ, Y Li, GL Adams, H Wagner, JA Kish, et al. (2003) An intergroup phase III comparison of standard radiation therapy and two schedules of concurrent chemoradiotherapy in patients with unresectable squamous cell head and neck cancer. J Clin Oncol, 21(1): 92-98.

4. Pignon JP, J Bourhis, C Domenge, L Designe (2000) Chemotherapy added to locoregional treatment for head and neck squamous-cell carcinoma: three meta-analyses of updated individual data MACH-NC Collaborative Group. Meta-Analysis of Chemotherapy on Head and Neck Cancer. Lancet 355(9208): 949-955.

5. Wendt TG, Grabenbauer GG, Rödel CM, Thiel HJ, Aydin H, et.al (1998) Simultaneous radio chemotherapy versus radiotherapy alone in advanced head and neck cancer: a randomized multicenter study. J Clin Oncol 16(4): 1318-1324.

6. Jeremic B, Shibamoto Y, Stanisavljevic B, Milojevic L, Milicic B, et al (1997) Radiation therapy alone or with concurrent low dose daily either cisplatin or carboplatin in locally advanced unresectable squamous cell carcinoma of the head and neck: a prospective randomized trial. Radiother Oncol 43(1): 29-37.

7. Brizel DM, Albers ME, Fisher SR, Scher RL, Richtsmeier WJ, et al. (1998) Hyper fractionated irradiation with or without concurrent chemotherapy for locally advanced head and neck cancer. N Engl J Med 338(25): 1798-1804.

8. Bachaud JM, Cohen Jonathan E, Alzieu C, David JM, Serrano E, et al. (1996) Combined postoperative radiotherapy and weekly cisplatin infusion for locally advanced head and neck carcinoma: final report of a randomized trial. Int J Radiat Oncol Biol Phys 36(5): 999-1004.

9. Wendt TG, Grabenbauer GG, Rödel CM, Thiel HJ, Aydin H, et al. (1998) Simultaneous radiochemotherapy versus radiotherapy alone in advanced head and neck cancer: a randomized multicenter study. J Clin Oncol 16: 1318-1324.

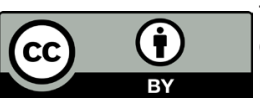

This work is licensed under Creative Commons Attribution 4.0 License DOI: 10.19080/CTOIJ.2019.14.555890
10. Brizel DM1, Albers ME, Fisher SR, Scher RL, Richtsmeier WJ, et al (1998) Hyperfractionated irradiation with or without concurrent chemotherapy for locally advanced head and neck cancer. N Engl J Med 338(25): 1798-1804.

11. Denis F, Garaud P, Bardet E, Alfonsi M, Sire C, et al. (2004) Final results of the 94-01 French Head and Neck Oncology and Radiotherapy Group randomized trial comparing radiotherapy alone with concomitant radiochemotherapy in advanced-stage oropharynx carcinoma. J Clin Oncol 22(1): 69-76.

12. Merlano M, Vitale V, Rosso R, Benasso M, Corvò R, et al. (1992) Treatment of advanced squamous-cell carcinoma of the head and neck with alternating chemotherapy and radiotherapy. New England Journal of Medicine 327(16): 1115-21.

13. Forastiere AA, Neuberg D, Deconti R, Adams G (1993) Phase Il evaluation of Taxol in advanced head and neck cancer: An Eastern Cooperative Oncology Group trial. J Natl Cancer Inst Monogr (15): 181-184.

14. Suntharalingam M, Haas ML, Conley BA, Egorin MJ, Levy S et al. (2000) The use of carboplatin and paclitaxel with daily radiotherapy in patients with locally advanced squamous cell carcinomas of the head and neck. Int J Radiat Oncol Biol Phys 47(1): 49-56.

15. Chougule PB, Akhtar MS, Akerley W, Ready N, Safran H, et al. (1999) Chemoradiotherapy for advanced inoperable head and neck cancer: a phase II study. Semin Radiat Oncol 9(2 Suppl 1): 58-63.

16. Chougule PB, Akhtar MS, Rathore R, Koness J, McRae R, et al. (2008) Concurrent chemoradiotherapy with weekly paclitaxel and carboplatin for locally advanced head and neck cancer: Long-term follow-up of a Brown University Oncology Group Phase II Study (HN-53). Head Neck 30(3): 289-96.

17. Garden AS, Harris J, Vokes EE, Forastiere AA, Ridge JA et al. (2004) Preliminary results of Radiation Therapy Oncology Group 97-03: a randomized phase II trial of concurrent radiation and chemotherapy for advanced squamous cell carcinomas of the head and neck J Clin Oncol 22(14): 2856- 2864.

18. Flood WA, Lee DJ, Trotti R, et al. (1996) A phase I study of weekly paclitaxel and cisplatin concurrent with postoperative radiation therapy for treatment of high-risk patients with squamous cell carcinoma of the head and neck. Proc Am Soc Clin Oncol 15: 314.

19. Agulnik M, Rhee EN, Yao M, Mundt AJ, Feldman LE (2005) Paclitaxel, carboplatin, and concomitant radiotherapy for resected patients with high risk head and neck cancer. J Chemother17(2): 237-241.

\section{Your next submission with Juniper Publishers will reach you the below assets}

- Quality Editorial service

- Swift Peer Review

- Reprints availability

- E-prints Service

- Manuscript Podcast for convenient understanding

- Global attainment for your research

- Manuscript accessibility in different formats

( Pdf, E-pub, Full Text, Audio)

- Unceasing customer service

Track the below URL for one-step submission https://juniperpublishers.com/online-submission.php 